\title{
Adverse Events Reactions Reported With the Use of a Fixed-Dose Combination of Nor-Pseudoephedrine, Triiodothyronine, Atropine, Aloin and Diazepam in Obese Mexican Patients
}

\author{
Cinthya Galicia-Quintanar ${ }^{1}$, Cecilia Fernández del Valle-Laisequilla ${ }^{1}$, Herman Soto-Molina², Eleazar Lara-Padilla ${ }^{1}$, Juan Carlos Huerta-
} Cruz $^{1}$, Juan Gerardo Reyes-García ${ }^{1 *}$

${ }^{1}$ Sección de Estudios de Posgrado e Investigación, Escuela Superior de Medicina, Instituto Politécnico Nacional, México, D.F., Mexico

${ }^{2}$ Universidad Autónoma Metropolitana Xochimilco, México, D.F., Mexico

\begin{abstract}
Background: Obesity is a health problem worldwide. Although the first-line intervention is implementing a comprehensive program of diet, exercise and behavior changes, some patients require additional drug treatment. Among the medications used wide and effectively for obesity in Mexico is found a combination consisting of 5 active ingredients: nor-pseudoephedrine, triiodothyronine, atropine, aloin and diazepam (Redotex®), whose rationality and safety remains controversial.
\end{abstract}

Objective: To analyze the adverse event reports received in the pharmacovigilance unit of the manufacturer company, from 2009 to 2014, in order to assess the existence of related potential safety issues.

Method: Adverse events were sorted by frequency and classified by intensity and causality. The groups mainly affected by adverse events by age and sex were determined and the pattern of comorbidities and use of concomitant drugs was defined.

Results: The number of reports recorded was 269 , which corresponded to 609 adverse events. The greater frequency of reports occurred in the group of female 18-50 years old. The main adverse events were dry mouth and polydipsia. Most adverse events were classified both as mild and probable. Among 132 patients who used concomitant medications, 64 of them corresponded to the use of additional anti-obesity products.

Conclusion: Except for some cases of misuse, there were no data to suspect the existence of special safety issues related with the use of the product; thus, considering the high anti-obesity efficacy reported for the study product (Redotex®), its adverse event profile seems acceptable.

Keywords: Adverse events; Obesity; Pharmacotherapy; Polydrug; Redotex ${ }^{\oplus}$; Safety

\section{Introduction}

Obesity is a chronic condition characterized by abnormal or excessive fat accumulation, which can be harmful to health $[1,2]$. Obesity is a public health issue and is considered a worldwide epidemic. In Mexico, from 1980 to 2012, the prevalence of obesity and overweight has been tripled in the adult population; thus, $42.6 \%$ of men and $39.5 \%$ of women are overweight and $26.8 \%$ of men and $37.5 \%$ of women are obese, resulting in approximately a $70 \%$ of adult Mexican population $(69.4 \%$ of men and $73.0 \%$ of women) with inadequate body mass index (BMI) [3]. Obesity is a risk factor for the development of serious diseases such as hypertension, dyslipidemia, type 2 diabetes, some cancers and other comorbidities, which in turn, are related to the decrease in expectancy and quality of life [4-6]. In contrast, modest weight reductions are beneficial in terms of reduced morbidity and mortality [7]. Although it has been established that obese subjects with $\mathrm{BMI} \geq 30$ should be incorporated into a comprehensive program that includes diet, exercise and behavioral strategies aimed at achieving a change in lifestyle that allows them to maintain a weight and BMI appropriate. Unfortunately, the usual pattern of weight loss in patients undergoing this intervention have been of limited effectiveness, where the maximum weight loss is reached within a few months, followed by a plateau stage and a gradual weight rebound over time [8]. Thus, current treatment recommendations contemplate the need to consider as candidates for drug treatment to those obese adults with BMI $>30$ $\mathrm{kg} / \mathrm{m}^{2}$ or those obese adults with BMI $\geq 27 \mathrm{~kg} / \mathrm{m}^{2}$ and comorbidities associated $[1,8,9]$.
In Mexico, in addition to orlistat, the use of classical anorectic products as clobenzorex, diethylpropion, mazindol and phentermine persists. Among this group there is one formulated with a combination of 5 active ingredients, in extended-release capsules, containing 50 $\mathrm{mg}$ of $\mathrm{D}$-norpseudoephedrine, $0.075 \mathrm{mg}$ of triiodothyronine, 0.36 $\mathrm{mg}$ atropine sulfate, $16 \mathrm{mg}$ of aloin and $8 \mathrm{mg}$ of diazepam (known as Redotex ${ }^{\otimes}$. This product is marketed in Mexico since 1956 and it is indicated as an adjuvant in the control of body weight in obese patients submitted to a proper diet and exercise regimen. Some studies have shown that the fixed-dose combination with 5 active ingredients (Redotex ${ }^{\otimes}$ ) decreases $12 \mathrm{~kg}$ to $14 \mathrm{~kg}$ of body weight in obese adults after 6 months of treatment, with an acceptable safety profile [10,11]. Notwithstanding the significant efficacy reported for the product, its rationality and safety have been questioned due the product is a

${ }^{*}$ Corresponding author: Juan Gerardo Reyes-García, Sección de Estudios de Posgrado e Investigación, Escuela Superior de Medicina, Instituto Politécnico Nacional, Plan de San Luis y Díaz Mirón s/n, Col. Casco de Santo Tomas, Del. Miguel Hidalgo, 11340 México, D.F. Mexico, Tel: 52552138 3602; Fax: 52555665 4623; E-mail: juangreyesgarcia@gmail.com

Received October 26, 2015; Accepted November 25, 2015; Published December 02, 2015

Citation: Galicia-Quintanar C, Valle-Laisequilla CF, Soto-Molina H, Lara-Padilla E, Juan Huerta-Cruz C, et al. (2015) Adverse Events Reactions Reported With the Use of a Fixed-Dose Combination of Nor-Pseudoephedrine, Triiodothyronine, Atropine, Aloin and Diazepam in Obese Mexican Patients. J Pharmacovigil 3: 185. doi:10.4172/2329-6887.1000185

Copyright: ( $) 2015$ Galicia-Quintanar C, et al. This is an open-access article distributed under the terms of the Creative Commons Attribution License, which permits unrestricted use, distribution, and reproduction in any medium, provided the original author and source are credited. 
Citation: Galicia-Quintanar C, Valle-Laisequilla CF, Soto-Molina H, Lara-Padilla E, Juan Huerta-Cruz C, et al. (2015) Adverse Events Reactions Reported With the Use of a Fixed-Dose Combination of Nor-Pseudoephedrine, Triiodothyronine, Atropine, Aloin and Diazepam in Obese Mexican Patients. J Pharmacovigil 3: 185. doi:10.4172/2329-6887.1000185

combination of 5 active ingredients. Thus, the objective of this study was to analyze the spontaneous reports of adverse events received in the pharmacovigilance unit of the manufacturer company, from 2009 to 2014 , in order to assess the existence of trends that could be potential safety risks associated the use of the product.

\section{Method}

The safety data were obtained from a database that collected all spontaneous case reports of the fixed-dose combination of norpseudoephedrine, triiodothyronine, atropine, aloin and diazepam $\left(\right.$ Redotex ${ }^{\oplus}$ ) received in the pharmacovigilance unit of the manufacturer company from January 2009 to December 2014. According to the spontaneous case reports, the adverse events were presented with an adequate fixed-dose combination dosing (a capsule once daily under fasting conditions). Adverse reports received by the pharmacovigilance officer were subsequently classified according to their intensity as 1) mild if they had signs and symptoms easily tolerated, did not need treatment nor prolonged hospitalization, and did not necessarily require stopping the medication; 2) moderate if they interfered with the activities of patient but without threaten his life, or if they required drug treatment, but not necessarily stopping the medication; or 3) severe if they interfered with daily activities and required drug treatment and medication suspension causing of adverse event. Additionally adverse events were classified by causality as 1) certain when the event is temporally related to the administration of the study product and it could not be explained by the natural evolution of the disease, concomitant diseases or the administration of other medications, and when the response to the suspension of the study product was clinically evident; as 2) probable when the event is temporally related to the administration of the study product and that could hardly be attributed to the natural evolution of the disease, concomitant diseases or other drug administration, and when the discontinuation of the study product gave a reasonable clinical response; as 3) possible when the event is temporally related to the administration of the study product and it could also be attributed to the natural evolution of the disease, concomitant diseases or other drug administration, and when the information about the suspension of the study product was not available or unclear; as 4) uncertain when the event is temporally independent of study product and it could be explained for the natural evolution of the disease, concomitant diseases or the administration of other drugs; as 5) conditional when the event could not be properly evaluated because more data are needed or that additional data are still being analyzed; and as 6) not assessable when the information gathered is insufficient or contradictory or the report could not be completed or verified [1].

Once the adverse events were classified by severity and causality, the main adverse events and the principal groups affected by age and gender were determined. In addition, the consumption patterns associated with comorbidities and concomitant medications were established and the main sets of adverse events were defined. All data were presented in frequency tables.

\section{Results}

\section{Demographic data and frequency of reports}

Table 1 shows the frequencies in age and gender of 269 spontaneous reports of adverse events associated with the use of the study product $\left(\right.$ Redotex $\left.^{\oplus}\right)$. The most of adverse events were observed in women of $18-50$ years of age, corresponding to over $90 \%$ of the reports. It is noteworthy that most of the reports were made by patients (192) and the rest (77) by physicians.

\section{Frequency of adverse events, severity and causality}

In the Table 2 are shown the individual frequencies of the 609 adverse events reported in the 269 cases for the fixed-dose combination (Redotex ${ }^{\circ}$. In the table can be showed that in both sexes the major adverse events consisted of dry mouth and polydipsia. In addition, women showed in much lesser degree, headache, dizziness and constipation. Regarding the severity of adverse events, 576 were classified as mild (94.5\%) and only 32 as moderate (5.3\%), being headache, constipation and upper abdominal pain the main adverse events found (Table 3). In addition, there was one case of goiter, which was classified as a severe adverse event. It is fair to say that there were no moderate or severe adverse events reported in men. With regard to causality, there was no any related certain adverse event, only 58 were considered probable, 537 were classified as possible and only 3 and 11 cases were classified as uncertain or conditional, respectively. On the other hand, it highlights the fact that despite containing five active ingredients the study product (Redotex $\left.{ }^{\circledR}\right)$, there were 12 reports of lack of efficacy.

\section{Number of adverse events per patient}

Of the 269 reports of adverse events, in 90 (34.6\%) cases, the report consisted of a single adverse event, in 83 (31.9\%) cases consisted of 2 adverse events, in $55(21.2 \%)$ cases were reported 3 adverse events, in 25 (9.6\%) cases were informed 4 adverse events, 11 (4.2\%) cases had registered 5 adverse events, in 7 (2.7\%) cases were reported 6 adverse events and in one case were informed 7 adverse events $(0.4 \%)$ and another one 8 adverse events $(0.4 \%)$, which means that approximately two-thirds of cases have more than one adverse event per patient.

\section{Reports of patients with comorbidities or concomitant medications}

Table 4 shows the frequencies of comorbidities and concomitantly administered drugs in patients with spontaneous reports of adverse reactions with the study product $\left(\operatorname{Redotex}^{\circ}\right)$. With respect to comorbidities stood out 27 cases of venous insufficiency (10.4\%), 16 cases of gastroesophageal reflux disease (6.2\%), 11 cases of dyslipidemia (4.2\%) and 11 cases of hypertension (4.2\%), while that in the cases of concomitantly administered drugs, there were surprisingly 64 cases of administration of additional anti-obesity drugs (24.6\%), in addition to 16 cases of concomitant use of hepatoprotective drugs (6.2\%), 11 cases with antihypertensive drugs (4.2\%) and 7 cases with contraceptives and hypoglycemic drugs in each $(2.7 \%)$. Data stratified by gender can be shown in Table 4.

\section{Sets of main adverse events}

Taking into consideration that dry mouth was the adverse event most commonly reported, followed by polydipsia, it was attempted to establish the existence of an adverse event profile, considering these

\begin{tabular}{|c|c|c|c|}
\hline Age (years) & Female & Male & Total \\
\hline$<18$ & 1 & 0 & 1 \\
\hline $18-30$ & 50 & 3 & 53 \\
\hline $31-40$ & 103 & 13 & 116 \\
\hline $41-50$ & 60 & 6 & 66 \\
\hline $51-60$ & 26 & 1 & 27 \\
\hline $61-70$ & 2 & 0 & 2 \\
\hline Unknown & 4 & 0 & 4 \\
\hline Total & 246 & 23 & $\mathbf{2 6 9}$ \\
\hline
\end{tabular}

Table 1: Number of adverse events reported spontaneously with the use of fixed dose combination of 5 active ingredients $\left(\right.$ Redotex $\left.^{\circledR}\right)$ classified by age and gender. 
Citation: Galicia-Quintanar C, Valle-Laisequilla CF, Soto-Molina H, Lara-Padilla E, Juan Huerta-Cruz C, et al. (2015) Adverse Events Reactions Reported With the Use of a Fixed-Dose Combination of Nor-Pseudoephedrine, Triiodothyronine, Atropine, Aloin and Diazepam in Obese Mexican Patients. J Pharmacovigil 3: 185. doi:10.4172/2329-6887.1000185

Page 3 of 6

\begin{tabular}{|c|c|c|c|c|c|c|c|}
\hline \multicolumn{8}{|c|}{ Adverse events } \\
\hline & $\mathbf{n}$ & Female & Male & & $\mathbf{n}$ & Female & Male \\
\hline Dry mouth & 180 & 162 & 18 & Hypertension & 2 & 2 & - \\
\hline Polydipsia & 104 & 91 & 13 & Hypotension & 2 & 2 & - \\
\hline Headache & 33 & 32 & 1 & Mood altered & 2 & 2 & - \\
\hline Dizziness & 26 & 26 & - & Delayed menstruation & 2 & 2 & - \\
\hline Constipation & 25 & 23 & 2 & Irregular menstruation & 2 & 2 & - \\
\hline Anxiety & 22 & 20 & 2 & Abnormal dreams & 2 & 2 & - \\
\hline Nausea & 18 & 18 & - & Tremor & 2 & 2 & - \\
\hline Irritability & 15 & 15 & - & Vertigo & 2 & 1 & 1 \\
\hline Drowsiness & 15 & 14 & 1 & Acne & 1 & 1 & - \\
\hline Nervousness & 14 & 13 & 1 & Arthralgia & 1 & 1 & - \\
\hline Lack of efficacy & 12 & 12 & - & Increased blood pressure & 1 & 1 & - \\
\hline Insomnia & 11 & 10 & 1 & Blepharospasm & 1 & 1 & - \\
\hline Fatigue & 9 & 9 & - & Goiter & 1 & 1 & - \\
\hline Asthenia & 7 & 7 & - & Dermatitis & 1 & 1 & - \\
\hline Tachycardia & 6 & 6 & - & Dyspnea & 1 & 1 & - \\
\hline Upper abdominal pain & 5 & 5 & - & Dyspepsia & 1 & 1 & - \\
\hline Dysgeusia & 4 & 4 & - & Periodontal disease & 1 & 1 & - \\
\hline Chills & 4 & 4 & - & Depressed mood & 1 & 1 & - \\
\hline Swelling & 4 & 4 & - & Vaginal bleeding & 1 & 1 & - \\
\hline Palpitations & 4 & 3 & 1 & Tenderness & 1 & 1 & - \\
\hline Paresthesia & 4 & 3 & 1 & Hypersomnia & 1 & 1 & - \\
\hline Weight gain & 3 & 3 & - & Lethargy & 1 & 1 & - \\
\hline Depression & 3 & 3 & - & Irregular bowel movements & 1 & 1 & - \\
\hline Diarrhea & 3 & 3 & - & Dry eyes & 1 & 1 & - \\
\hline Decreased appetite & 3 & 3 & - & Oliguria & 1 & 1 & - \\
\hline Hyperphagia & 3 & 3 & - & Pale skin & 1 & 1 & - \\
\hline Hyperhidrosis & 3 & 3 & - & Oral paresthesia & 1 & 1 & - \\
\hline Restlessness & 3 & 3 & - & Pyrexia & 1 & 1 & - \\
\hline Halitosis & 3 & 3 & - & Polymenorrhea & 1 & 1 & - \\
\hline Fluid retention & 3 & 2 & 1 & Proteinuria & 1 & 1 & - \\
\hline Vomit & 3 & 3 & - & Pruritus & 1 & 1 & - \\
\hline Alopecia & 2 & 2 & - & Weight reduction & 1 & 1 & - \\
\hline Renal colic & 2 & 2 & - & Urinary retention & 1 & - & 1 \\
\hline Abdominal distension & 2 & 1 & 1 & Sultriness & 1 & 1 & - \\
\hline Dysuria & 2 & 2 & - & Irritable bowel syndrome & 1 & 1 & - \\
\hline Eye edema & 2 & 2 & - & Flushing & 1 & 1 & - \\
\hline Dry throat & 2 & 1 & 1 & Urticaria & 1 & - & 1 \\
\hline \multicolumn{5}{|c|}{ Total } & 609 & 562 & 47 \\
\hline
\end{tabular}

Table 2: Type of adverse events reported spontaneously with the use of the fixed-dose combination of 5 active ingredients (Redotex ${ }^{\circledR}$ )

two events. It was notorious that in $148(56.9 \%)$ cases the dry mouth ( 88 cases, $33.8 \%$ ) or dry mouth and polydipsia (60 cases, $23.1 \%)$ were the only adverse events reported. In a lesser degree ( 7 cases, $2.7 \%)$, these symptoms were associated with headache, dizziness, constipation and nausea. Finally, in a very low number of cases, dry mouth, polydipsia, headache, dizziness, constipation, and nausea were associated with other symptoms as anxiety ( 1 case, $0.4 \%)$ or with drowsiness and nervousness ( 1 case, $0.4 \%$ ), Table 5 .

\section{Discussion}

The high prevalence of obesity worldwide stand out the need to use several strategies to counteract this important health issue [3,12]. In various guidelines for the treatment of obesity is established that obese adults with BMI $>30 \mathrm{~kg} / \mathrm{m}^{2}$ or BMI $\geq 27 \mathrm{~kg} / \mathrm{m}^{2}$ and associated comorbidities are candidates for pharmacotherapy $[1,8]$. Multimodal pharmacotherapy for obesity treatment can help obese patients lose weight and maintain the weight loss [13]. Currently, a number of drugs such as phentermine, diethylpropion, clobenzorex, mazindol, orlistat and some fixed-dose combinations are approved in Mexico, as adjuvants to caloric restriction, exercise and behavior modification, for the treatment of obesity. Fixed-dose combinations are acceptable when showing advantages over single compounds administered separately in therapeutic effect, safety and adherence or where toxicity is reasonable [14].

In this regard, the current study analyzed the safety of a fixed-dose combination of 5 active ingredients (Redotex ${ }^{\otimes}$ ), which is widely used for the treatment of obesity with reductions of average weight of about $13 \mathrm{~kg}$ [10]. According to the literature, the rational basis supporting the fixed-dose combination of nor-pseudoephedrine, triiodothyronine, atropine, aloin and diazepam (Redotex ${ }^{\circledR}$ consist in the activation of some drugs with different antiobesity action mechanisms that increase the effectiveness of individual drugs, and some others that help to improve the safety profile. Thus, D-norpseudoephedrine reduces body lipid content by activation adrenergic receptors that increases the appetite threshold and exerts a thermogenic effect $[11,15]$. Triiodothyronine increases the fat catabolism enhancing sympathetic activation and 
Citation: Galicia-Quintanar C, Valle-Laisequilla CF, Soto-Molina H, Lara-Padilla E, Juan Huerta-Cruz C, et al. (2015) Adverse Events Reactions Reported With the Use of a Fixed-Dose Combination of Nor-Pseudoephedrine, Triiodothyronine, Atropine, Aloin and Diazepam in Obese Mexican Patients. J Pharmacovigil 3: 185. doi:10.4172/2329-6887.1000185

Page 4 of 6

\begin{tabular}{|c|c|c|c|}
\hline \multicolumn{4}{|c|}{ Adverse events } \\
\hline \multicolumn{4}{|c|}{ Moderate } \\
\hline & $\mathrm{n}$ & & $\mathrm{n}$ \\
\hline Headache & 4 & Face swelling & 1 \\
\hline Constipation & 4 & Drowsiness & 1 \\
\hline Upper abdominal pain & 3 & Irregular menstruation & 1 \\
\hline Anxiety & 2 & Nervousness & 1 \\
\hline Dry mouth & 2 & Palpitations & 1 \\
\hline Hypertension & 2 & Paresthesia & 1 \\
\hline Acne & 1 & Irritable bowel syndrome & 1 \\
\hline Blepharospasm & 1 & Drowsiness & 1 \\
\hline Renal colic & 1 & Tachycardia & 1 \\
\hline Dyspnea & 1 & Urticaria & 1 \\
\hline Dysuria & 1 & & \\
\hline \multicolumn{4}{|c|}{ Severe } \\
\hline & $\mathrm{n}$ & & \\
\hline Goiter & 1 & & \\
\hline
\end{tabular}

Table 3: Number of moderate and severe adverse events reported spontaneously with the use of study product (Redotex $\left.{ }^{\circledast}\right)$ in women. There were no moderate or severe adverse events in men.

\begin{tabular}{|c|c|c|c|c|c|c|c|}
\hline Comorbidities & $\mathbf{n}$ & Female & Male & Concomitant medications & $\mathbf{n}$ & Female & Male \\
\hline Venous insufficiency & 27 & 27 & - & Antiobesity drugs & 64 & 64 & - \\
\hline Gastroesophageal reflux disease & 16 & 16 & - & Hepatoprotectives & 16 & 11 & 5 \\
\hline Dyslipidemia & 11 & 9 & 2 & Antihypertensive & 8 & 3 & 5 \\
\hline Hypertension & 11 & 6 & 5 & Contraceptives & 7 & 7 & - \\
\hline Irritable bowel disease & 8 & 8 & - & Hypoglycemic & 7 & 7 & - \\
\hline Anxiety & 8 & 8 & - & Analgesics & 6 & 6 & - \\
\hline Back pain & 6 & 6 & - & Venotonics & 4 & 4 & - \\
\hline Fatty liver & 5 & 5 & - & Vitamins & 4 & 4 & - \\
\hline Constipation & 4 & 4 & - & Anxiolytics & 3 & 3 & - \\
\hline Gallstones & 4 & 4 & - & Lipid-lowering drugs & 2 & 2 & - \\
\hline Urinary tract infection & 3 & 3 & - & Probiotics & 2 & 2 & - \\
\hline Depression & 3 & 3 & - & Laxatives & 2 & 2 & - \\
\hline Diabetes & 3 & 3 & - & Antibiotics & 2 & 2 & - \\
\hline Allergies & 2 & 1 & 1 & Anti-anemics & 1 & 1 & - \\
\hline Hypothyroidism & 2 & 2 & - & Thyroid drugs & 1 & 1 & - \\
\hline Insomnia & 2 & 2 & - & Anti-ulcers & 1 & 1 & - \\
\hline Anemia & 1 & 1 & - & Diuretics & 1 & 1 & - \\
\hline Sore throat & 1 & 1 & - & Anticholinergics & 1 & 1 & - \\
\hline Goiter & 1 & 1 & - & & & & \\
\hline Total & 118 & 110 & 8 & Total & 132 & 122 & 10 \\
\hline
\end{tabular}

Table 4: Number of adverse events reported spontaneously with the use of study product (Redotex ${ }^{\circledR}$ ) in patients with comorbidities or concomitant medications.

\begin{tabular}{|c|c|c|c|c|}
\hline Number of adverse events & \multicolumn{3}{|c|}{ Set of adverse events } & \\
\hline 1 & Dry mouth & & & \\
\hline 2 & Dry mouth & Polydipsia & \\
\hline 6 & Dry mouth & Polydipsia & $\begin{array}{c}\text { Headache } \\
\text { Constipation } \\
\text { Dizziness } \\
\text { Nausea }\end{array}$ \\
\hline 7 & Dry mouth & Polydipsia & $\begin{array}{c}\text { Headache } \\
\text { Constipation } \\
\text { Dizziness } \\
\text { Nausea }\end{array}$ & 7 \\
\hline 8 & Dry mouth & Polydipsia & $\begin{array}{c}\text { Headache } \\
\text { Constipation } \\
\text { Dizziness } \\
\text { Nausea }\end{array}$ & Anxiety \\
\hline & & & $\begin{array}{c}\text { Drowsiness } \\
\text { Nervousness }\end{array}$ & 1 \\
\hline
\end{tabular}

Table 5: Main sets of adverse events reported spontaneously with the use of study product (Redotex ${ }^{\circledR}$. 
Citation: Galicia-Quintanar C, Valle-Laisequilla CF, Soto-Molina H, Lara-Padilla E, Juan Huerta-Cruz C, et al. (2015) Adverse Events Reactions Reported With the Use of a Fixed-Dose Combination of Nor-Pseudoephedrine, Triiodothyronine, Atropine, Aloin and Diazepam in Obese Mexican Patients. J Pharmacovigil 3: 185. doi:10.4172/2329-6887.1000185

reducing leptin [11,16-18]. Diazepam decreases the anxiety associated to obesity, and consequently the bulimic neurosis with binge eating often present in the obese [11,19]. Aloin is a compound derivate of aloe with a mild laxative effect that counteracts the diminution of gastrointestinal motility induced by atropine and the constipation associated frequently in the obesity $[11,20,21]$. Atropine reduces the salivary and gastric secretions inhibiting the physiological hunger [11]. However, since that formulation consists of 5 active ingredients, its rational basis can be questioned in terms of safety.

In the present study was showed that obese patients mainly affected by adverse events with the use of a fixed-dose combination of norpseudoephedrine, tri-iodothyronine, atropine, aloin and diazepam (Redotex ${ }^{*}$ ) were female between 18 and 50 years old. This issue seems to follow a specific usage pattern of the study product, more than a special predisposition of group. Actually, the higher incidence of adverse events in this group could be explained for the concomitant use of other antiobesity drugs. Concordantly, Morin and colleagues report in an effectiveness study of this drug $\left(\right.$ Redotex $\left.^{\circ}\right)$ performed in 22 medical offices that female are the predominant population ( 250 of 288 patients, $86.8 \%$ ) with a mean age of $38.6 \pm 9.7$ years old. In a similar way, a controlled study carried out with the fixed-dose combination $\left(\right.$ Redotex $\left.^{\circ}\right)$ in obese volunteers point out that the women are the majority population ( 179 of 210 volunteers, $85.2 \%$ ) with an average age of $36 \pm 9$ years old $[10,11]$.

The adverse events most frequently reported with the use of the fixed-dose combination of nor-pseudoephedrine, triiodothyronine, atropine, aloin and diazepam $\left(\right.$ Redotex $\left.^{\circledR}\right)$ in both sexes were dry mouth and polydipsia. In addition women presented in a minor degree headache, dizziness, constipation, anxiety, nausea, irritability, drowsiness, nervousness and insomnia, as well as other even less frequent as fatigue, asthenia, tachycardia and abdominal pain. Moreover, it is fair to note the existence of 12 cases of adverse events in women related to lack of efficacy. Xerostomia or dry mouth associated with polydipsia is one of the most common adverse events of antagonist muscarinic, atropine [22], and it is also related to sympathetic stimulation, in this case by nor-pseudoephedrine [23,24]. In fact, dry mouth is suggested as a marker of the efficacy of some anorexigenic sympathetic stimulants [25]. On the other hand, the lack of efficacy reported in 12 women can be explained by the multifactorial origin of obesity [26], making clear that even a certain group of obese patients not responding to treatment with multiple drugs. Regarding safety global profile and frequency of reported adverse events, it was found that adverse events broadly corresponds to the expected, according to the common adverse events listed in the monographs of the individual products. In addition, $94.6 \%$ of adverse events reported were mild, $5.3 \%$ were moderate and $0.1 \%$ was severe. Among the main moderate adverse events, there are 4 events of headache, 4 events of constipation, 3 events of upper abdominal pain, 2 events of dry mouth, 2 events of anxiety, 2 events of hypertension and others with only one adverse event, all in women. The severe adverse event corresponded to goiter of undetermined etiology. However, there were not found potential adverse events with the combination as atrial fibrillation, myocardial infarction, hyperthyroidism, thyrotoxicosis, cardiac arrhythmia, hypersensitivity, increased intraocular pressure, respiratory depression or neutropenia [22,27-30]. The absence of severe adverse event reports with the combination could be due to that this product is mainly used by a young female population, which was slightly vulnerable.
In general, the profile of frequent adverse events included dry mouth either alone or accompanied with polydipsia, or these two symptoms together with headache, constipation, dizziness and nausea. The sets of adverse events observed do not appear to represent a safety issue special in the most of patients, however, a small group of patients had simultaneously between 7 and 8 adverse events, although the relevance of this small group could not be identified due to the absence of a follow-up mechanism.

In the analysis of reports of patients with comorbidities were distinguished some cases of hypertension, diabetes and insomnia due these comorbidities are contraindications of the study product in the approved prescribing information in Mexico [31]. Similarly, in the analysis of reports of patients with concomitant medications showed the concurrent use of other anti-obesity drugs and even thyroid drugs, especially in women, which can be considered as misuse of this prescription product.

Even considering the limited number of adverse events reported during five years and the lack of follow-up of adverse events, except for the few cases of abuse or misuse of the product, results seems indicate that the safety profile and frequency of adverse events observed in the analysis was favorable for the product, especially considering its high effectiveness in obesity $[10,11]$, and the lack of particular trends related to potential safety problems.

\section{Acknowledgement}

All the authors' kindly acknowlegde Productos Medix, S.A. de C.V., Mexico City, Mexico for the information provided for this study. This work was part of the M.Sc. dissertation of Cinthya Galicia-Quintanar.

\section{References}

1. Chavarría Arciniega S (2002) Definición y criterios de obesidad. Nutrición Clínica 5: 236-40.

2. Ortiz Domínguez ME (2010) Norma Oficial Mexicana NOM-008-SSA3-2010 para el tratamiento integral del sobrepeso y la obesidad. Diario Oficial de la Federación.

3. Gutiérrez JP, Rivera-Dommarco J, Shamah-Levy T, Villalpando-Hernández S, Franco A, et al. (2012) Encuesta Nacional de Salud y Nutrición 2012. Resultados Nacionales. Cuernavaca, México: Instituto Nacional de Salud Pública 1-196.

4. Nguyen DM, El-Serag HB (2010) The epidemiology of obesity. Gastroenterol Clin North Am 39: 1-7.

5. Selassie M, Sinha AC (2011) The epidemiology and aetiology of obesity: a global challenge. Best Pract Res Clin Anaesthesiol 25: 1-9.

6. Malnick SD, Knobler H (2006) The medical complications of obesity. QJM 99: 565-579.

7. Williamson DF, Pamuk E, Thun M, Flanders D, Byers T, et al. (1995) Prospective study of intentional weight loss and mortality in never-smoking overweight US white women aged 40-64 years. Am J Epidemiol 141: 1128-1141.

8. Jensen MD, Ryan DH, Apovian CM, Ard JD, Comuzzie AG, et al. (2013) 2013 AHA/ACC/TOS guideline for the management of overweight and obesity in adults: a report of the American College of Cardiology/American Heart Association Task Force on Practice Guidelines and The Obesity Society. Circulation 129: S102-S138.

9. Delaet D, Schauer D (2011) Obesity in adults. BMJ Clin Evid 2011: 0604.

10. Zaragoza RM, Villanueva GL, Oritz RA, Huerta DR (2001) Comparación de dos formulaciones de d-norpseudoefedrina y placebo en pacientes obesos tratados durante seis meses. Med Int Mex 17: 260-271

11. Morín Zaragoza R, Rodríguez Choreño JD, Morales Suárez MO, Rodríguez Almaraz JE (2014) Experiencia clínica con fórmula combinada como tratamiento farmacológico (en liberación prolongada) a corto plazo contra la obesidad. Rev Hosp Jua Mex 81: 154-160. 
Citation: Galicia-Quintanar C, Valle-Laisequilla CF, Soto-Molina H, Lara-Padilla E, Juan Huerta-Cruz C, et al. (2015) Adverse Events Reactions Reported With the Use of a Fixed-Dose Combination of Nor-Pseudoephedrine, Triiodothyronine, Atropine, Aloin and Diazepam in Obese Mexican Patients. J Pharmacovigil 3: 185. doi:10.4172/2329-6887.1000185

Page 6 of 6

12. Ogden CL, Carroll MD, Curtin LR, McDowell MA, Tabak CJ, et al. (2006) Prevalence of overweight and obesity in the United States, 1999-2004. JAMA 295:1549-1555.

13. Dietz WH, Goodwin NJ, Hill JO, Pi-Sunyer FJ, Rolls B, et al. (1996) Long-term pharmacotherapy in the management of obesity. National Task Force on the Prevention and Treatment of Obesity. JAMA 276: 1907-1915.

14. Gautam CS, Saha L (2008) Fixed dose drug combinations (FDCs): rational or irrational: a view point. Br J Clin Pharmacol 65: 795-796.

15. Arch JR, Ainsworth AT, Cawthorne MA (1982) Thermogenic and anorectic effects of ephedrine and congeners in mice and rats. Life Sci 30: 1817-1826.

16. Hochberg I, Hochberg Z (2010) Expanding the definition of hypothalamic obesity. Obes Rev 11: 709-721.

17. Krotkiewski M (2000) Thyroid hormones and treatment of obesity. Int J Obes Relat Metab Disord 24: S116-119.

18. Reinehr T (2010) Obesity and thyroid function. Mol Cell Endocrinol 316: 165-171.

19. Pirke KM, Platte P (1998) Psychosomatic aspects of obesity. Zentralbl Gynakol 120: 251-254.

20. Surjushe A, Vasani R, Saple DG (2008) Aloe vera: a short review. Indian J Dermatol 53: 163-166.
21. Mushref MA, Srinivasan S (2013) Effect of high fat-diet and obesity on gastrointestinal motility. Ann Transl Med 1: 14.

22. Atropine (2015) In Martindale. The complete Drug Reference.

23. Munro JF, MacCuish AC, Wilson EM, Duncan LJ (1968) Comparison of continuous and intermittent anorectic therapy in obesity. Br Med J 1: 352-354.

24. Zöller H, Rückert KH (1973) Effect of the anorexic agent phentermine hydrochloride on haemodynamics. Munch Med Wochenschr 115: 1244-1248.

25. Zahorska-Markiewicz B (1980) Salivation for the measurement of the anorectic effectiveness of mazindol. Curr Ther Res 27: 868-874.

26. Hussain SS, Bloom SR (2011) The pharmacological treatment and management of obesity. Postgrad Med 123: 34-44.

27. Triiodothyronine (2015) In Martindale. The complete Drug Reference.

28. Pseudoephedrine (2015) In Martindale. The complete Drug Reference.

29. Diazepam (2015) In Martindale. The complete Drug Reference.

30. Aloe (2015) In Martindale. The complete Drug Reference.

31. Redotex ${ }^{\circledast}$ (2015) In PLM $^{\circledast}$ Lider en Informacion sobre Ciencias de la Salud. 